\title{
The Association between Right Ventricular Function and Exercise Capacity for Hypertensive Patients
}

Ragab A. Mahfouz, El-Sayed M. Farag, Radwa A. Elbelbesy, Ahmed K. Hassaan

Department of Cardiology, Faculty of Medicine, Zagazig University Hospital, Egypt

*Corresponding Author: Ahmed K. Hassaan, E-Mail: ahmed.khal.has@gmail.com

\begin{abstract}
Background: Transthoracic echocardiography (TTE) would be used to evaluate right ventricular (RV) function in patients with arterial hypertension, and the link between RV dysfunction and exercise capacity was studied in the study population.

Objective: To establish a correlation with exercise capability in the study group by using transthoracic echocardiography (TTE) to evaluate RV function in patients with arterial hypertension.

Patients and Methods: Patients with hypertension were surveyed in a cross-sectional research; those known and treated; whether controlled or not and patients who were recently discovered to be hypertensive. Ninety patients were included; gender and age were taken into account. A thorough examination was performed on each patient (TTE) as well as six minute walking distance (6MWD). For all we had a written informed consent prior to enrollment.

Results: Patients with untreated and uncontrolled hypertension showed significantly reduced right ventricular systolic and diastolic functions compared to those with well-controlled hypertension. Patients with untreated or uncontrolled hypertension had significant $(\mathrm{P}<0.001)$ deterioration on $\mathrm{S}$ ', wave and diastolic dysfunction parameters $(\mathrm{E} / \mathrm{A}, \mathrm{DTt}, \mathrm{E} / \mathrm{e} \mathrm{t}$ and IVRT). Untreated and uncontrolled hypertension patients showed a significant decrease in 6MWD compared to the well-controlled individuals $(\mathrm{P}<0.001)$.

Conclusion: Untreated or ineffectively treated hypertension individuals had considerably reduced right ventricular function and exercise capacity, according to our findings. In the entire research population, right ventricular functions are strongly linked to exercise ability.
\end{abstract}

Keywords: 6 minute walk test, Echocardiography, Exercise capacity, Hypertension, Right ventricle

\section{INTRODUCTION}

In contrast to left ventricle (LV) hypertension, there is a lack of reliable evidence that hypertension affects the RV. Research into the RV can be done in several ways, including using imaging and functional methods. When assessing RV structure and function, echocardiography is the primary tool ${ }^{(\mathbf{1})}$.

When it comes to RV dysfunction, coronary artery disease has been the most widely studied topic. RV ejection fraction has been determined in individuals with and without the right coronary artery blockage. There have also been studies done on the patterns of asynergy of RV in both acute as well as chronic coronary disease (2). Assessment of functional exercise capacity in patients with moderate to severe heart or lung illness can be done by conducting the six-minute walk test (6MWT) ${ }^{(3)}$.

When the left ventricle is subjected to the chronic pressure overload that occurs in essential hypertension, little is known about RV performance. It's because the two ventricles influence each other's performance because of their distorted geometry. Furthermore, no research has examined the possible link between exercise capacity and right ventricular function in hypertension patients ${ }^{(3)}$.

The aim of the present study by using transthoracic echocardiography (TTE) to evaluate RV function in patients with arterial hypertension, so as to establish a correlation with exercise capability in the study group.

\section{PATIENTS AND METHODS}

Zagazig University Hospital's Cardiology Department's outpatient clinic hosted our study from March 2021 to October 2021. 90 patients with hypertension were included divided into 3 groups; 30 well controlled, 30 recently diagnosed untreated and 30 treated patients with unsatisfactory blood pressure control. The following factors were used to determine whether or not a candidate was eligible: Primary systemic arterial hypertension had already been diagnosed before to the trial. (When repeatedly systolic pressure (SP) equal or higher than $140 \mathrm{~mm} \mathrm{Hg}$ and/or diastolic pressure (DP) equal or higher than $90 \mathrm{~mm} \mathrm{Hg}$ ) (4).

\section{Exclusion criteria:}

Patients $<18$ years, patients with significant valvular heart disease, hypertrophic or infiltrative cardiomyopathy, those who were experiencing atrial fibrillation and had an abnormally low left ventricular systolic function (Ejection fraction lower than fifty percent), pericardial diseases, acute coronary syndrome, inability to perform 6MWT and/or poor acoustic window, chronic obstructive pulmonary disease (COPD), asthma and sleeping disorders, chronic kidney disease (CKD) and chronic liver disease, peripheral vascular disease, patients with musculoskeletal diseases and arthropathies, patients with decompensated heart failure (HF), patients with tachyarrhythmias and bradyarrhythmias, morbidly obese patients, patients with pulmonary hypertension, patients with severe 
anemia, diabetes mellitus (DM) with peripheral neuropathy and adult congenital heart disease of any type.

\section{The patients were subjective to:}

History of smoking or dyslipidemia or positive family history of labile hypertension, weight, height measurements as well as laboratory investigations (fasting blood glucose, complete blood count, triglycerides, total cholesterol, uric acid in addition to serum creatinine), along with the use of antihypertensive medication, All patients who participated in the trial were surveyed. Each patient's body mass index (BMI) and body surface are (BSA) were calculated. Thorough physical examination to evaluate the patients with contraindication of 6MWT (CAD and HF). ECG was done for all patients to detect $\mathrm{LVH}$, tachyarrhythmia and bradyarrhythmia or any ischemic changes that rule out the patient from the study.

\section{Echocardiography:}

All patients had echocardiography performed with the use of Siemens acuson p500 (Siemens; Healthcare, California, USA, 2019) in accordance with the American Society of Echocardiography guidelines. Doppler flow tracing registration at the tricuspid as well as mitral valves was then performed as part of routine echocardiogram. Echo-Doppler readings were evaluated using the average of five cardiac cycles in order to decrease the variability that occurs during the breathing cycles ${ }^{(\mathbf{5})}$.

\section{RV systolic function:}

A conventional AP4 window was used for RV function assessment according to the American Society of Cardiology (ASE). By using at least one or a combination of the following, RV systolic function can be evaluated TAPSE, FAC, or $\mathrm{S}^{\prime}$ wave. E and A peak velocities $(\mathrm{m} / \mathrm{sec}), \mathrm{E} / \mathrm{A}$ ratio, E wave deceleration time (ms), RV isovolumetric relaxation time (ms), which was defined as the time interval from the end of pulmonary outflow to the commencement of tricuspid inflow, were used to calculate the RV global filling measurements ${ }^{(5)}$.
When TAPSE was less than $1.7 \mathrm{~cm}$ or S' was less than $9.5 \mathrm{~cm} / \mathrm{s}(0.95 \mathrm{~m} / \mathrm{s}), \mathrm{RV}$ systolic dysfunction was observed. (a) E/A 0.8, (b) E/A from 0.8 to 2.1 and E/E' $>6$, and (c) E/A greater than 2.1 and deceleration duration shorter than $120 \mathrm{~ms}$ indicated RV diastolic dysfunction ${ }^{(6)}$.

\section{The 6MWT is used to measure functional capacity}

American Thoracic Society (ATS) criteria were followed for the 6-minute walking test. There was a 30meter hallway with cones at each ends that was used for all 6MWT (ATS, 2002) ${ }^{(7)}$.

\section{Ethical consent:}

An approval of the study was obtained from Zagazig University Academic and Ethical Committee. Every patient signed an informed written consent for acceptance of participation in the study. This work has been carried out in accordance with The Code of Ethics of the World Medical Association (Declaration of Helsinki) for studies involving humans.

\section{Statistical analysis}

The collected data were coded, processed and analyzed using the SPSS (Statistical Package for the Social Sciences) version 22 for Windows ${ }^{\circledR}$ (IBM SPSS Inc, Chicago, IL, USA). Data were tested for normal distribution using the Shapiro Wilk test. Qualitative data were represented as frequencies and relative percentages. Chi square test $\left(\chi^{2}\right)$ was used to calculate difference between groups of qualitative variables. Quantitative data were expressed as mean \pm SD (Standard deviation). Independent samples t-test was used to compare between two independent groups of normally distributed variables (parametric data). $\mathrm{P}$ value $<0.05$ was considered significant.

\section{RESULTS}

The study population was evenly distributed in terms of age and gender. In terms of body mass index (BMI), there was a substantial difference between the two groups tested (BSA) (Table 1).

Table (1): The study population's demographics

\begin{tabular}{|c|c|c|c|c|}
\hline & $\begin{array}{c}\text { Controlled HTN } \\
\qquad(\mathbf{N}=\mathbf{3 0})\end{array}$ & $\begin{array}{l}\text { Untreated HTN } \\
\qquad(\mathbf{N}=\mathbf{3 0})\end{array}$ & $\begin{array}{l}\text { Uncontrolled } \\
\text { HTN }(\mathbf{N}=30)\end{array}$ & $\mathbf{p}$ \\
\hline $\begin{array}{c}\text { Age (years): } \\
\text { Mean } \pm \text { SD }\end{array}$ & $54 \pm 3$ & $54 \pm 4$ & $55 \pm 2$ & 0.758 \\
\hline $\begin{array}{c}\text { Sex: } \\
\text { Male } \\
\text { Female } \\
\end{array}$ & $\begin{array}{l}20(66.7 \%) \\
10(33.3 \%)\end{array}$ & $\begin{array}{l}20(66.7 \%) \\
10(33.3 \%)\end{array}$ & $\begin{array}{l}20(66.7 \%) \\
10(33.3 \%)\end{array}$ & 1 \\
\hline $\begin{array}{c}\text { BMI }\left(\mathbf{k g} / \mathbf{m}^{\mathbf{2}}\right) \\
\text { Mean } \pm \text { SD }\end{array}$ & $24.5 \pm 0.6$ & $26.5 \pm 0.6$ & $27.4 \pm 0.6$ & $<0.001$ \\
\hline $\begin{array}{c}\text { BSA }\left(\mathbf{m}^{\mathbf{2}}\right) \\
\text { Mean } \pm \text { SD }\end{array}$ & $1.93 \pm 0.013$ & $1.96 \pm 0.015$ & $1.99 \pm 0.013$ & $<0.001$ \\
\hline
\end{tabular}

Untreated and uncontrolled hypertension patients had higher average SBP and DBP than well-treated individuals (Table 2). 
Table (2): Systolic and Diastolic BP, average 2-3 office visits

\begin{tabular}{|ccccc|}
$\begin{array}{c}\text { Daytime blood } \\
\text { pressure }\end{array}$ & $\begin{array}{c}\text { Controlled } \\
\text { HTN }(\mathbf{N}=\mathbf{3 0})\end{array}$ & $\begin{array}{c}\text { Untreated } \\
\text { HTN }(\mathbf{N}=\mathbf{3 0})\end{array}$ & $\begin{array}{c}\text { Uncontrolled } \\
\text { HTN }(\mathbf{N}=\mathbf{3 0})\end{array}$ & p \\
$\begin{array}{c}\text { SBP }(\mathbf{m m H g}) \\
\text { Mean } \pm \text { SD }\end{array}$ & $122 \pm 5$ & $152 \pm 8$ & $145 \pm 5$ & $<0.001$ \\
\hline $\begin{array}{c}\text { DBP }(\mathbf{m m H g}) \\
\text { Mean } \pm \text { SD }\end{array}$ & $72 \pm 6$ & $88 \pm 5$ & $87 \pm 7$ & $<0.001$ \\
\hline
\end{tabular}

LV: IVS thickness and PW thickness increased significantly in both untreated and uncontrolled hypertension patients compared to those who were effectively treated (Table 3).

Table (3): A study population's left ventricular anatomy measurements using echocardiographic parameters (2DE and M-mode)

\begin{tabular}{|ccccc|}
\hline Parameter & $\begin{array}{c}\text { Controlled } \\
\text { HTN }(\mathbf{N}=\mathbf{3 0})\end{array}$ & $\begin{array}{c}\text { Untreated } \\
\text { HTN }(\mathbf{N}=\mathbf{3 0})\end{array}$ & $\begin{array}{c}\text { Uncontrolled } \\
\text { HTN }(\mathbf{N}=\mathbf{3 0})\end{array}$ & $\mathbf{p}$ \\
\hline $\begin{array}{c}\text { LVEDD }(\mathbf{m m}) \\
\text { Mean } \pm \text { SD }\end{array}$ & $49.6 \pm 7.6$ & $50.3 \pm 7.8$ & $51.4 \pm 8.8$ & 0.253 \\
\hline $\begin{array}{c}\text { LVESD (mm) } \\
\text { Mean } \pm \text { SD }\end{array}$ & $32.9 \pm 7.6$ & $32.6 \pm 4.8$ & $32.4 \pm 5.6$ & 0.496 \\
\hline $\begin{array}{c}\text { IVS (mm) } \\
\text { Mean } \pm \text { SD }\end{array}$ & $9.2 \pm 3.2$ & $12.9 \pm 5.1$ & $13.1 \pm 4.1$ & $<0.001$ \\
\hline $\begin{array}{c}\text { EF }(\boldsymbol{\%}) \\
\text { Mean } \pm \text { SD }\end{array}$ & $63 \pm 6.1$ & $62 \pm 6.3$ & $62 \pm 5.2$ & 0.078 \\
\hline $\begin{array}{c}\text { PW } \\
\text { Mean } \pm \text { SD }\end{array}$ & $9.8 \pm 2$ & $13 \pm 4$ & $13.4 \pm 5$ & $<0.001$ \\
\hline
\end{tabular}

A gradual decline in the trans-mitral E/A ratio occurred from the well-controlled patients to the untreated and ineffectively treated ones. The deceleration time for the trans-mitral deceleration was, on the other hand, steadily increasing (Table 4)

Table (4): Echocardiographic parameters of left-ventricular function in the study population (Pulsed Doppler)

\begin{tabular}{|ccccc|}
\hline Pulsed Doppler & $\begin{array}{c}\text { Controlled } \\
\text { HTN }(\mathbf{N}=\mathbf{3 0})\end{array}$ & $\begin{array}{c}\text { Untreated } \\
\text { HTN }(\mathbf{N}=\mathbf{3 0})\end{array}$ & $\begin{array}{c}\text { Uncontrolled } \\
\text { HTN }(\mathbf{N}=30)\end{array}$ & p \\
\hline $\begin{array}{c}\text { E/A ratio } \\
\text { Mean } \pm \text { SD }\end{array}$ & $1.26 \pm 0.36$ & $0.87 \pm 0.32$ & $0.82 \pm 0.22$ & $<0.001$ \\
\hline $\begin{array}{c}\text { DT }(\mathbf{m s}) \\
\text { Mean } \pm \text { SD }\end{array}$ & $197 \pm 48$ & $221 \pm 40$ & $234 \pm 34$ & $<0.001$ \\
\hline
\end{tabular}

RV: Right ventricular wall thickness rose from the well-controlled to the uncontrolled hypertensive individuals over a period of few months. Non-significant results were found in the study population for TAPSE and FAC (Table 5).

Table (5): Study participants' right ventricular anatomy measurements using echocardiography (2DE and M-mode)

\begin{tabular}{|ccccc|}
\hline $\begin{array}{c}\text { Parameter } \\
\begin{array}{c}\text { RV lat. wall thickness } \\
\text { Mean } \pm \text { SD }\end{array}\end{array}$ & $\begin{array}{c}\text { Controlled } \\
\text { HTN }(\mathbf{N}=\mathbf{3 0})\end{array}$ & $\begin{array}{c}\text { Untreated } \\
\text { HTN }(\mathbf{N}=\mathbf{3 0})\end{array}$ & $\begin{array}{c}\text { Uncontrolled } \\
\text { HTN }(\mathbf{N}=\mathbf{3 0})\end{array}$ & p \\
\hline $\begin{array}{c}\text { TAPSE }(\mathbf{m m}) \\
\text { Mean } \pm \text { SD }\end{array}$ & $21 \pm 3.1$ & $21 \pm 1.3$ & $20.3 \pm 3.2$ & 0.194 \\
\hline $\begin{array}{c}\text { FAC }(\boldsymbol{\%}) \\
\text { Mean } \pm \text { SD }\end{array}$ & $41 \pm 4.8$ & $40 \pm 5.6$ & $40 \pm 6.5$ & 0.336 \\
\hline
\end{tabular}

For untreated hypertension individuals, the $\mathrm{S}^{\prime}$ wave and parameters of right-ventricular diastolic dysfunction (E/A, DTt, E/e and IVRT) were dramatically deteriorated (Table 6). 
Table (6): Echocardiographic measures of right ventricular function (Pulsed Doppler and DTI) in the study population

\begin{tabular}{|ccccc|}
\hline Parameter & $\begin{array}{c}\text { Controlled } \\
\text { HTN }(\mathbf{N}=\mathbf{3 0})\end{array}$ & $\begin{array}{c}\text { Untreated HTN } \\
(\mathbf{N}=30)\end{array}$ & $\begin{array}{c}\text { Uncontrolled } \\
\text { HTN }(\mathbf{N}=30)\end{array}$ & p \\
\hline $\begin{array}{c}\text { RVS' wave (cm/sec) } \\
\text { Mean } \pm \text { SD }\end{array}$ & $13 \pm 1.3$ & $10.4 \pm 1.5$ & $10.3 \pm 1.4$ & $<0.001$ \\
\hline $\begin{array}{c}\text { (E/A) t } \\
\text { Mean } \pm \text { SD }\end{array}$ & $1.2 \pm 0.3$ & $0.96 \pm 0.2$ & $0.84 \pm 0.2$ & $<0.001$ \\
\hline $\begin{array}{c}\text { DT t }(\mathbf{m s}) \\
\text { Mean } \pm \text { SD }\end{array}$ & $174 \pm 28$ & $187 \pm 24$ & $198 \pm 43$ & $<0.001$ \\
\hline $\begin{array}{c}\text { E/e' t } \\
\text { Mean } \pm \text { SD }\end{array}$ & $3.5 \pm 1.6$ & $5.6 \pm 1.2$ & $5.8 \pm 1.3$ & $<0.001$ \\
\hline $\begin{array}{c}\text { SPAP }(\mathbf{m m H g}) \\
\text { Mean } \pm \text { SD }\end{array}$ & $20 \pm 3$ & $20 \pm 5$ & $21 \pm 2$ & 0.965 \\
\hline $\begin{array}{c}\text { IVRT (m/s) } \\
\text { Mean } \pm \text { SD }\end{array}$ & $83 \pm 2.3$ & $93 \pm 2.4$ & $97 \pm 2.5$ & $<0.001$ \\
\hline
\end{tabular}

Functional capacity assessed by 6MWD: Untreated or uncontrolled patients' 6MWD was much shorter than those who were in a well-controlled group that had accomplished a greater distance (Table 7).

Table (7): Comparison of the six-minute walk distance between the three studied groups

\begin{tabular}{|ccccc|}
\hline Parameter & $\begin{array}{c}\text { Controlled } \\
\text { HTN }(\mathbf{N}=30)\end{array}$ & $\begin{array}{c}\text { Untreated } \\
\text { HTN }(\mathbf{N}=30)\end{array}$ & $\begin{array}{c}\text { Uncontrolled } \\
\text { HTN }(\mathbf{N}=30)\end{array}$ & p \\
\hline $\begin{array}{l}\text { 6MWD (m) } \\
\text { Mean } \pm \text { SD }\end{array}$ & $626.0 \pm 35.8$ & $426.0 \pm 35.8$ & $406.0 \pm 35.8$ & $<0.001^{* *}$ \\
\hline LSD & $\mathrm{P}_{1}<0.001^{* *}$ & $\mathrm{P}_{2} 0.033^{*}$ & $\mathrm{P}_{3}<0.001^{* *}$ & \\
\hline
\end{tabular}

There was statistically significant negative correlation between six minute walk distance and each of BSA, BMI, RVWT, SBP and DBP, DTt, E/e't, and IVRT among the studied patients ( $\mathrm{P}<0.001)$. There was statistically significant positive correlation between 6MWD and each of TAPSE, FAC, RV S' (Figure 1), (E/A ratio) (Figure 2) and RV (E/A ratio) among the studied patients (Figure 3$)(\mathrm{P}<0.001)$.

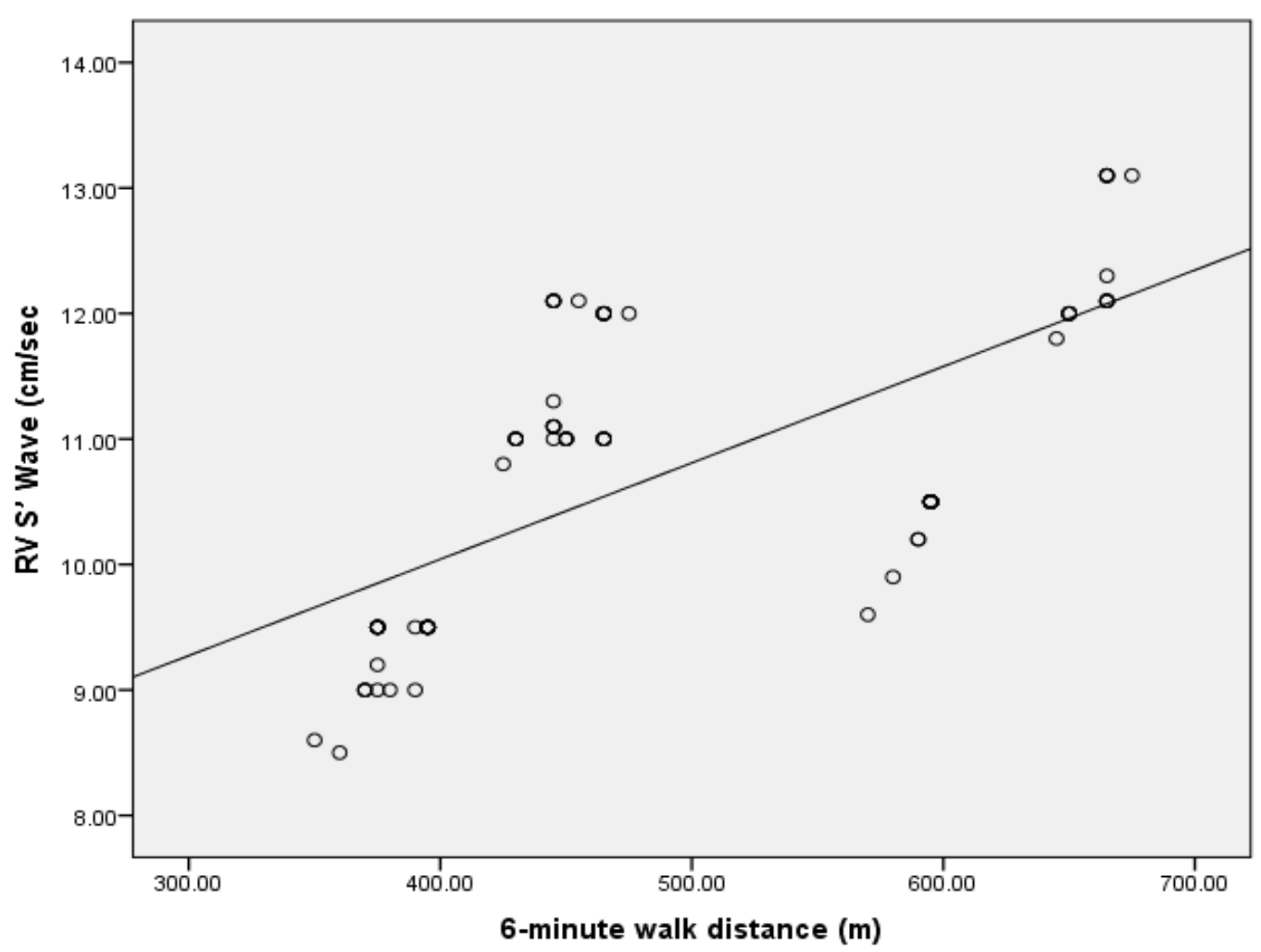

Figure (1): A positive correlation between 6MWD and RV S' wave in the study population 
https://ejhm.journals.ekb.eg/

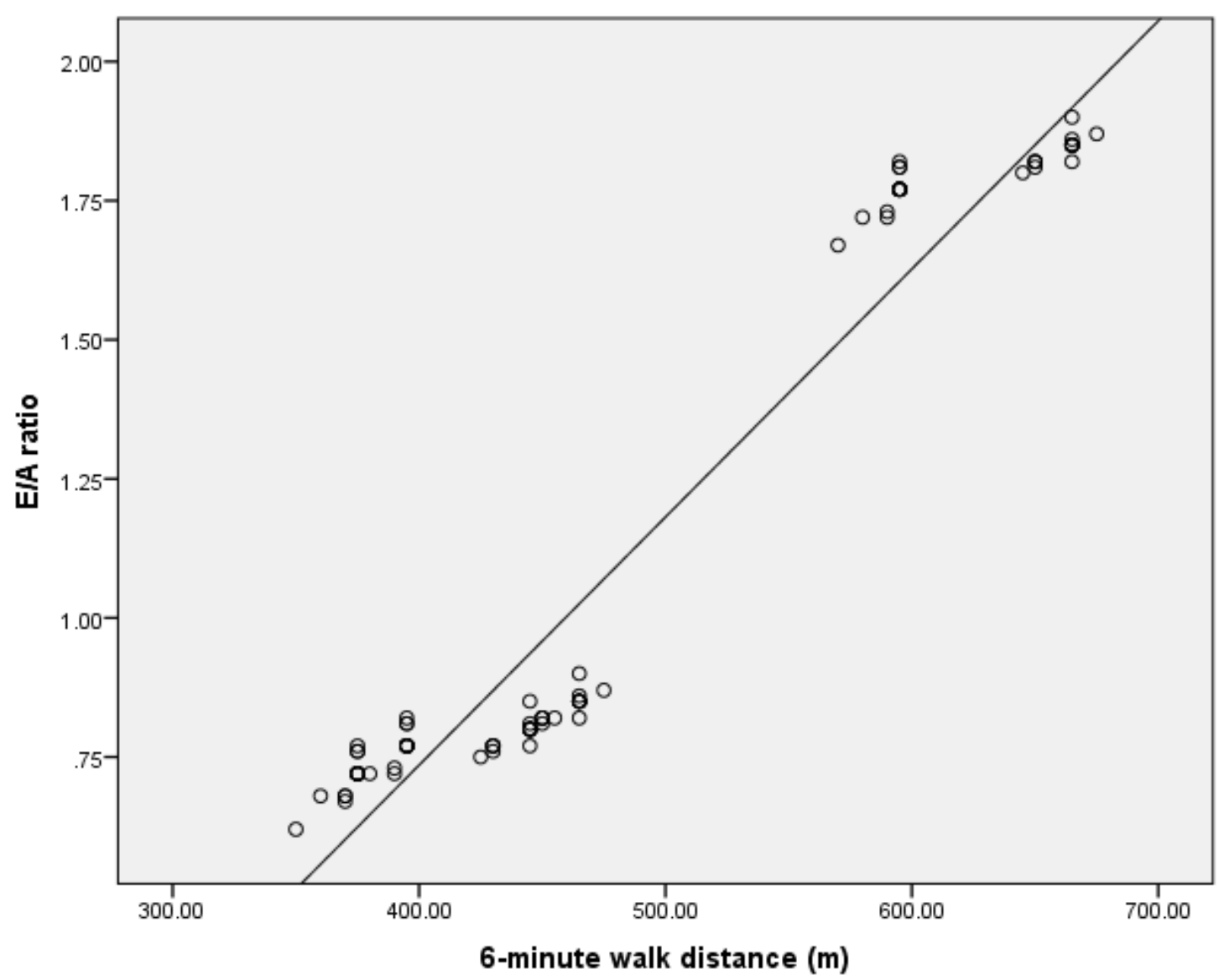

Figure (2): A positive connection between 6MWD and LV (E/A ratio) in the research population

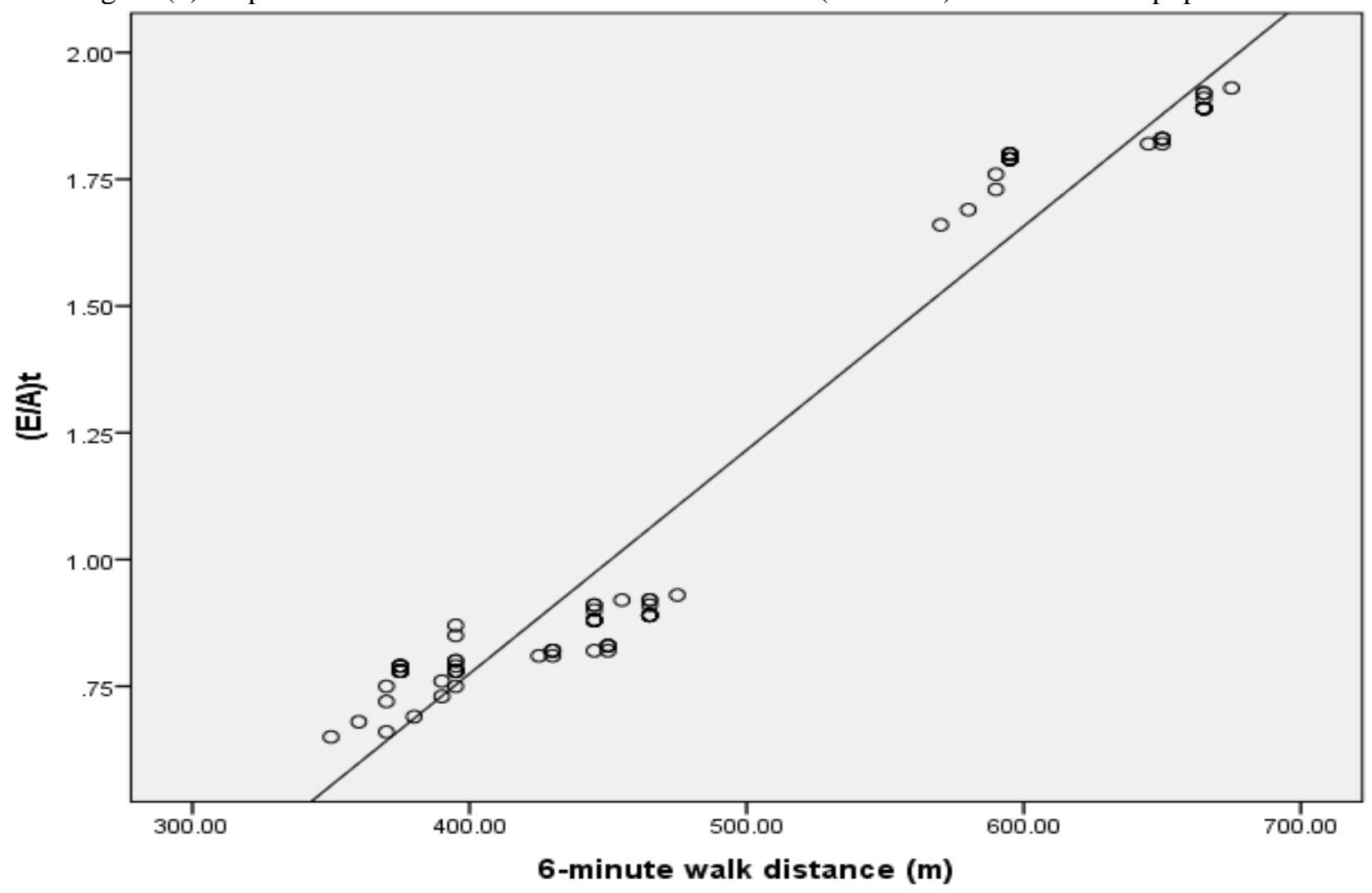

Figure (3): A positive connection between 6MWD and RV (E/A ratio) in the research population 


\section{DISCUSSION}

For the first time, this study examined the relationship between RV dysfunction, as measured by TTE, and 6MWT in patients with and without treatment for hypertension. In terms of body mass index (BMI), there was a substantial difference between the two groups tested (BSA). The difference was significant between each two individual groups (highest in uncontrolled hypertensive groups followed by untreated group then well controlled group). High blood pressure (hypertension) can be prevented or delayed by making healthy lifestyle choices, according to our research. Antihypertensive medication therapy can also be enhanced by lifestyle adjustment, which is the first line of treatment for hypertension. Sagaro and colleagues ${ }^{(8)}$ studied the relationship of SBP with BMI and showed that both SBP and DBP were positively linked with BMI (p 0.01). As a result, a weight-loss programme should be prioritised in order to treat high blood pressure.

As evaluated by TAPSE, there was no statistically significant difference between the three groups studied. Results reported by Cicale et al. ${ }^{(9)}$, who studied 30 hypertensive patients and Tumuklu et al. ${ }^{(10)}$ who studied 35 hypertensive patients, and Abdeltawab et al. ${ }^{(11)}$, who studied 90 patients with hypertension found normal TAPSE among studied groups.

Our results were discordant with others, Ojji et al. ${ }^{(12)}$ and Oketona et al. ${ }^{(13)}$ who found that $53 \%$ and $44.5 \%$ of hypertensive patients had abnormal TAPSE. This difference may be attributed to the fact that they studied RVSD in hypertensive HF.

According to recent guidelines, RVSD was found if RV, TAPSE $<17 \mathrm{~mm}$ and tricuspid pulsed Doppler S' wave $<9.5 \mathrm{~cm} / \mathrm{s}$ or FAC $<35 \%{ }^{(\mathbf{5}, 15)}$. Accordingly, RVSD was found in $33.3 \%$ of uncontrolled hypertensive patients and $26.7 \%$ of untreated hypertensive patients based on S' wave $<9.5 \mathrm{~cm} / \mathrm{s}$. These results were in agreement with Karaye et al. ${ }^{(15)}$, who found RVSD in $29.6 \%$ of untreated hypertensive patients. Pedrinelli $\boldsymbol{e t}$ al. (1), found that $S$ ' wave was reduced in mildly hypertensive patients and in high normal blood pressure group when compared to normotensive group. Hanboly (16) found that The RVSD was found in $30 \%$, among the uncontrolled hypertensive patients.

Our results were discordant with, Oketona et al. ${ }^{(13)}$ and Ifeoluwa et al. ${ }^{(17)}$ who found that $40.8 \%$ and $48 \%$ of uncontrolled hypertensive patients had RVSD. This difference in the results was attributed to that they studied RVSD in hypertensive HF.

In this study, RV diastolic dysfunction was characterised as either stage I (TV E/A less than 0.8, suggesting poor relaxation), stage II (TV E/A greater than 2.1, suggesting pseudonormal filling), or stage III (TV E/A ratio greater than 2.1) ${ }^{(18)}$. According to these criteria, RVDD was found in $36.7 \%$ of untreated hypertensive patients and $66.7 \%$ of uncontrolled hypertensive patients, furthermore, our study demonstrated that RVDD accompanied LVDD that was due to hypertensive heart disease as the mitral and tricuspid (E/A ratio) were shown to have a significant positive correlation in the study population (0.001). Akintunde et al. ${ }^{(19)}$ and Ganesh and Srinivas (20) determined that RV functional abnormalities as well as morphological changes are linked to systemic hypertension, and that RVDS may be an early warning sign of hypertensive heart disease. Pedrinelli et al. (1) found the septal thickness to be adversely linked with RVSD and RVDD.

In concordance with our study, Abdeltawab et al. (11), found that patients with stage II hypertension had considerably thicker IVS and PW as compared to stage I HTN and control groups. There was a statistically significant correlation between the existence of hypertension and RV diastolic function using Doppler data from the tricuspid valve $(\mathrm{p}<0.001)$.

Retrograde transmission of higher diastolic pressure from a stiffer LV or an increase in pulmonary resistance could explain abnormal RV functioning in arterial hypertension ${ }^{(21)}$. Hypertensive individuals have a lower E/A ratio and an increased transmitral deceleration time, hence it is plausible to consider the previous mechanism as genuine for this group of patients.

The pulmonary resistance was not measured in this investigation, although the systolic pressure in the pulmonary artery was comparable among the groups. This study does not support the idea that pulmonary resistance has an impact on RV function in systemic hypertension.

When arterial hypertension is present, the increased systemic afterload immediately affects the RV's ability to pump blood. Hypertensive individuals who were untreated or uncontrolled had considerably thicker IVS and PW as compared to hypertensive patients who were under treatment according to our findings.

Hypertensive individuals' functional capacity has been shown in previous studies to be lowered. Dekleva et al. ${ }^{(22)}$, Ramos et al. ${ }^{(23)}$, Farag et al. ${ }^{(24)}$ and Harshada et al. ${ }^{(25)}$. According to our research, this is exactly what happened. Untreated or uncontrolled patients' 6MWD was much shorter than those who were in a wellcontrolled group that had accomplished a greater distance. In addition, we discovered that SBP and 6MWT had a negative connection, which is consistent with earlier researches by Sekiguchi et al. ${ }^{(26)}$, Tadic and Ivanovic ${ }^{(21)}$ and Farag et al. ${ }^{\text {(24) }}$.

The present study, revealed positive correlation of the mitral and tricuspid (E/A ratio) in the study population. The relationship between the right heart's functional capability and the LV-to-RV interaction could be explained by this process.

Since earlier studies have shown a correlation between LV anatomy and function and functional capability, our findings are consistent with those of prior researchers, e.g. Ogunyemi et al. ${ }^{(27)}$ and Farag et al. ${ }^{(24)}$. The high link between the left and right ventricular functions was obtained mostly through the IVS, as was also found by Dibble $\boldsymbol{e t}$ al. ${ }^{(28)}$ and Tadic and Ivanovic 
(21). This research may help to establish a link between proper heart function and functional capacity. The relationship between the right heart's functional capability and the LV-to-RV interaction could be explained by this process.

The strength of our study is that we were able to demonstrate that right ventricular function is linked to exercise capacity in hypertension patients.

\section{CONCLUSION}

The idea that $\mathrm{RV}$ is immune to the negative effects of hypertension is no longer a valid one. An early indicator of systemic arterial hypertension, as well as a sign of well-controlled hypertension, was shown to be $\mathrm{RV}$ function. Patients with systemic arterial hypertension should have their RV function assessed by echocardiography, as RV function is linked to exercise capability.

\section{Financial support and sponsorship: Nil. Conflict of interest: Nil.}

\section{REFERENCES}

1. Pedrinelli R, Canale M, Giannini C et al. (2010): RV dysfunction in early systemic hypertension: a tissue Doppler imaging study in patients with high-normal and mildly increased arterial blood pressure. J Hypertens., 28: 615-621.

2. Mattoo T (2010): Hypertension in pediatric patients. Indian Pediatr., 47: 473-474.

3. Hamm L, Wenger $\mathrm{N}$, Arena $\mathrm{R}$ et al. (2013): Cardiac rehabilitation and cardiovascular disability: role in assessment and improving functional capacity. J Cardio-pulm Rehabil Prev., 33: 1-11

4. Unger T, Borghi C, Charchar F et al. (2020): 2020 International Society of Hypertension Global Hypertension Practice Guidelines. Hypertension, 75: 1334-1357.

5. Roberto $M$, Luigi $P$, Victor $M$ et al. (2015): Recommendations for cardiac chamber quantification by echocardiography in adults: An update from the American Society of Echocardiography and the European Association of Cardiovascular Imaging. J Am Soc Echocardiogr., 28:1-39

6. Rudski L, Lai W, Afilalo J et al. (2010): Guidelines for the echocardiographic assessment of the right heart in adults: a report from the American Society of Echocardiography endorsed by the European Association of Echocardiography, a registered branch of the European Society of Cardiology, and the Canadian Society of Echocardiography. J Am Soc Echocardiogr., 23: 685-713.

7. ATS Statement (2002): guidelines for the 6-min walking test. Am J Respir Crit Care Med., 166: 111 -117.

8. Sagaro G, Battineni G, Di Canio M et al. (2021): Selfreported modifiable risk factors of cardiovascular disease among seafarers: A Cross-Sectional Study of Prevalence and Clustering. Journal of Personalized Medicine, 11: 512-16.

9. Cicale S, Galderisi M, Caso P et al. (2002): RV diastolic dysfunction in arterial systemic hypertension: Analysis by pulsed tissue Doppler. Eur J Echocardiogr., 3: 135 - 142.

10. Tumuklu M, Erkorkmaz U, Ocal A et al. (2007): The impact of hypertension and hypertension-related LV hypertrophy on RV function. J of CV Ultrasound and Allied Tech., 24: 4-10.

11. Abdeltawab A, Eweda I, Mostafa A et al. (2018): Relation of RV function to presence and degree of systemic hypertension. J Cardiovasc Dis Diagn., 6: 306-11.
12. Ojji B, Lecour S, Atherton J et al. (2016): RV systolic dysfunction is common in hypertensive heart failure: a prospective study in sub-Saharan Africa. PLoS One, 11(4): 153-58.

13. Oketona O, Balogun M, Akintomide A et al. (2017): RV systolic function in hypertensive heart failure. Vascular Health and Risk Management, 13: 353-360.

14.Surkova E, Kovács A (2020): Comprehensive echocardiographic assessment of the RV performance: Beyond TAPSE and fractional area change. Russian Journal of Cardiology, 25(3):4067-71.

15. Karaye K, Habib A, Mohammed S et al. (2010): Assessment of RV systolic function using tricuspid annular-plane systolic excursion in Nigerians with systemic hypertension. Cardiovasc J Afr., 21: 186-190.

16. Hanboly H (2016): RV morphology and function in systemic hypertension. Nigerian Journal of Cardiology, 13: 11-17

17. Ifeoluwa A, Adebiyi A, Adeoye A et al. (2019): RV systolic function in subjects with heart failure secondary to hypertensive heart disease. Afri Health Sci., 19(2): 2130-2139.

18. Lang R, Badano L, Mor-Avi $V$ et al. (2015): Recommendations for cardiac chamber quantification by echocardiography in adults: an update from the American Society of Echocardiography and the European Association of Cardiovascular Imaging. Eur Heart J Cardiovasc Imaging, 16: 233-270.

19. Akintunde A, Akinwusi P, Familoni O et al. (2010): Effect of systemic hypertension on RV morphology and function: an echocardiographic study. Cardiovascular journal of Africa, 21: $1-5$.

20.Ganesh G, Srinivas S (2019): Impact of asymptomatic hypertension on left and right ventricular functions by echocardiography. National Journal of Physiology, Pharmacy and Pharmacology, 9: 1-6.

21. Tadic M, Ivanovic B (2014): Why is functional capacity decreased in hypertensive patients? From mechanisms to clinical studies. J Cardiovasc Med., 15: 447-455.

22.Dekleva M, Lazic J, Pavlovic M et al. (2012): Cardiopulmonary exercise testing and its relation to oxidative stress in patients with hypertension. Hypertens Res., 35:11451151

23. Ramos R, Guimara es F, Cordovil I et al. (2014): The sixminute walk distance is a marker of hemodynamic-related functional capacity in hypertension: a case-control study. Hypertension Research, 37: 746-752.

24. Farag E, Al-Daydamony M, Gad M (2017): What is the association between left ventricular diastolic dysfunction and 6-minute walk test in hypertensive patients? J Am Soc Hypertens., 11(3):158-164.

25. Harshada S, Anagha A, Kumar A (2020): Correlation of functional capacity and quality of life in hypertensive post menopausal females. International Journal of Health Sciences and Research, 10: 1-5.

26. Sekiguchi M, Adachi H, Oshima $S$ et al. (2009): Effect of changes in left ventricular diastolic function during exercise on exercise tolerance assessed by exercise-stress tissue Doppler echocardiography. Int Heart J., 50:763 - 771.

27. Ogunyemi S, Balogun M, Akintomide A et al. (2012): Cardiovascular responses to treadmill exercise in Nigerian hypertensives with left ventricular hypertrophy. Niger J Clin Pract., 15:199 - 205.

28. Dibble C, Lima J, Bluemke D et al. (2011): Regional left ventricular systolic function and the right ventricle: the multiethnic study of atherosclerosis right ventricle study. Chest, 140: $310-316$. 